\title{
Potential Risk of Food-Drug Interactions: Citrus Polymethoxyflavones and Flavanones as Inhibitors of the Organic Anion Transporting Polypeptides (OATP) 1B1, 1B3, and 2B1
}

\author{
Gzona Bajraktari-Sylejmani ${ }^{1}$. Johanna Weiss ${ }^{1}$ (i)
}

Published online: 13 July 2020

(c) The Author(s) 2020

\begin{abstract}
Background and Objectives Citrus flavonoids are not only components of daily nutrition, they are also promoted as dietary supplements and are important ingredients in traditional medicines. Interactions of flavonoids with synthetic drugs represent an often neglected issue. We therefore investigated in vitro whether the polymethoxyflavones nobiletin, sinensetin, and tangeretin and the flavonoid rutinosides didymin, hesperidin, and narirutin can inhibit human organic anion transporting polypeptides (OATP) 1B1, 1B3, and 2B1, which are important transporters mediating drug-drug and food-drug interactions. Methods Inhibition was investigated by quantifying the decreased uptake of the fluorescent OATP1B1 and OATP1B3 substrate 8-fluorescein-cAMP in HEK293 cells overexpressing OATP1B1 or OATP1B3 and of the fluorescent OATP2B1 substrate 4',5'-dibromofluorescein in HEK293 cells overexpressing OATP2B1.

Results We demonstrate that all flavonoids investigated inhibit OATP2B1 in the lower micromolar range $\left(\mathrm{IC}_{50}\right.$ between 1.6 and $14.2 \mu \mathrm{M}$ ), but only the polymethoxyflavones also inhibit OATP1B1 and $1 \mathrm{~B} 3\left(\mathrm{IC}_{50}\right.$ between 2.1 and $\left.21 \mu \mathrm{M}\right)$.

Conclusions All flavonoids investigated might contribute to the intestinal OATP2B1-based interactions with drugs observed with citrus juices or fruits. In contrast, the concentration of the polymethoxyflavones after consumption of citrus juices or fruits is most likely too low to reach relevant systemic concentrations and thus to inhibit hepatic OATP1B1 and OATP1B3, but there might be a risk when they are consumed as medicines or as dietary supplements.
\end{abstract}

\section{Key Points}

Citrus polymethoxyflavones and flavone rutinosides inhibit OATP2B1, and the polymethoxyflavones also inhibit OATP1B1 and OATP1B3.

Ingestion of these compounds might lead to interactions with OATP substrates.

Caution is recommended when using these compounds as a functional food or medicine.

Johanna Weiss

johanna.weiss@med.uni-heidelberg.de

1 Department of Clinical Pharmacology and Pharmacoepidemiology, University Hospital Heidelberg, University of Heidelberg, Im Neuenheimer Feld 410, 69120 Heidelberg, Germany

\section{Introduction}

Flavonoids are secondary metabolites of plants and fungi and thus belong to daily nutritional components [1]. The 7- $O$-rutinoside-flavanones hesperidin, narirutin, and didymin are abundant in the pulp and juice of Citrus sinensis, Citrus clementina, and Citrus reticulata, whereas the polymethoxyflavones nobiletin, sinensetin, and tangeretin are abundant predominantly in several citrus peels, but also in citrus juices, e.g., of Citrus clementina and Citrus sinensis (Fig. 1) [2-5]. They exhibit many biologic activities such as anti-oxidative, anti-inflammatory, anti-cancer, anti-viral, neuroprotective, and cardiovascular protective effects $[2$, 6-12] and are thus promoted as dietary supplements. Moreover, at least nine traditional Chinese medicines are derived from different Citrus species with the polymethoxyflavones being the most important ingredients $[8,9]$.

The concentrations of the polymethoxyflavones nobiletin, sinensetin, and tangeretin in the pulp or juice of ripe citrus fruits is not very high compared to the diverse flavonoid 
Fig. 1 Chemical formula of the flavonoids investigated<smiles>COc1ccc(-c2cc(=O)c3c(OC)c(OC)c(OC)c(OC)c3o2)cc1OC</smiles><smiles>COc1ccc(-c2cc(=O)c3c(OC)c(OC)c(OC)cc3o2)cc1OC</smiles><smiles>COc1ccc(-c2cc(=O)c3c(OC)c(OC)c(OC)c(OC)c3o2)cc1</smiles><smiles></smiles><smiles>COc1ccc(C2CC(=O)c3c(O)cc(Oc4cc(O)c5c(c4)C(O)C(O)C(OC4OC6C(O)C(O4)C6O)O5)cc3O2)cc1O</smiles>

Hesperidin<smiles></smiles>

glycosides such as hesperidin, narirutin, and naringenin [3-5]. However, due to their methylated hydroxy groups and thus higher hydrophobicity, the polymethoxyflavones are predicted to exhibit a much higher intestinal absorption and metabolic stability than the hydroxy-flavonoids [2, 13]. Moreover, whereas the rutinosides hesperidin, narirutin, and didymin are hydrolyzed to their aglycones by the colonic microflora before absorption and thus do not reach systemic circulation [14-16], the polymethoxyflavones can reach the systemic circulation unchanged.

Organic anion transporting polypeptides (OATPs) represent a superfamily of sodium-independent transmembrane transporters expressed in many tissues critical for drug pharmacokinetics such as intestine or liver [17-21]. They mediate the uptake of a wide range of mostly anionic organic molecules including endogenous compounds such as bile acids and conjugated steroids, but also numerous drugs such as statins. OATP1B1 and OATP1B3 are mainly expressed on the basolateral membrane of hepatocytes and thus play an important role in hepatic drug uptake and elimination. OATP2B1 is more widely expressed including the apical site of enterocytes mediating intestinal drug uptake [19, 20, 22]. OATP inhibitors can decrease (inhibition of intestinal OATP2B1) or increase (inhibition of hepatic OATP1B1/1B3) plasma concentrations of substrate drugs triggering drug-drug or food-drug interactions [17-23]. In contrast to the widely expressed OATP2B1, for which inhibition by citrus fruit/juice/flavonoids provoking interactions with drugs has already been demonstrated [19, 23, 24], the role of the liver-specific OATP1B 1 and OATP1B3 in mediating citrus-drug interactions is less clear, and the effect of polymethoxyflavones and the 7-O-rutinoside-flavanones on these transporters is completely unknown. We therefore investigated in vitro whether the 7- $O$-rutinoside-flavanones and the polymethoxyflavones could inhibit human OATP1B1 and OATP1B3 and also tested OATP2B1 inhibition, which was so far untested for sinensetin, didymin, and narirutin.

\section{Materials and Methods}

\subsection{Materials}

Cell culture media, supplements, Hank's buffered salt solution (HBSS), phosphate-buffered saline (PBS), a cytotoxicity detection kit (LDH), 4',5'-dibromofluorescein (DBF), tetracycline, rifampicin, naringin (purity $\geq 95 \%$ ), hesperidin (purity $\geq 98 \%$ ), and narirutin (purity $\geq 98 \%$ ) were obtained from Sigma-Aldrich (Taufkirchen, Germany). Fetal calf serum (FCS) was purchased from Biochrom (Berlin, Germany). Dimethyl sulfoxide (DMSO) was from AppliChem (Darmstadt, Germany). 8-Fluorescein-cAMP (8-FcA) was 
purchased from BIOLOG Life Science Institute (Bremen, Germany). Sinensetin (purity $\geq 98 \%$ ) was purchased from Cayman (Biomol, Hamburg, Germany), tangeretin (purity $\geq 99 \%$ ) from Phytolab (Vestenbergsgreuth, Germany), nobiletin (purity $\geq 99 \%$ ) from Hycultec (Beutelsbach, Germany), and didymin (purity $\geq 99 \%$ ) from Extrasynthese (Geney, France).

\subsection{Stock Solutions}

Stock solutions $(100 \mathrm{mM})$ of all compounds were prepared in DMSO at room temperature and were stored in aliquots at $-80^{\circ} \mathrm{C}$. Dilutions were made directly before usage in the respective buffer used for the assays (PBS/2\% FCS for the uptake assays, HBSS for the cytotoxicity assays).

\subsection{HEK-OATP1B1 and HEK-OATP1B3 Cells}

The human embryonic kidney cell line HEK293 stably transfected with organic anion transporter polypeptide 1B1 (OATP1B1) (HEK-OATP1B1), OATP1B3 (HEKOATP1B3), or the empty control vector (HEK293-VC G418) was used to assess inhibition of OATP1B1 and OATP1B3 [25, 26]. The cell lines were a generous gift of Dr. D. Keppler (German Cancer Research Centre, Heidelberg, Germany) and characterized previously [25, 26]. After receipt, the cell lines were authenticated by quantifying the OATP1B1 and OATP1B3 mRNA expression by reverse transcription quantitative polymerase chain reaction (qRT-PCR). The overexpression of the respective OATP compared to the mock control was confirmed in each assay by using the control inhibitor rifampicin. Cells were cultured under standard cell culture conditions with DMEM supplemented with $10 \%$ FCS, $2 \mathrm{mM}$ glutamine, $100 \mathrm{U} / \mathrm{ml}$ penicillin, $100 \mu \mathrm{g} / \mathrm{ml}$ streptomycin sulfate, and $800 \mu \mathrm{g} / \mathrm{ml} \mathrm{G} 418$.

\subsection{HEK-OATP2B1 Cells}

HEK293 cells overexpressing OATP2B1 in the presence of tetracycline were a kind gift of Dr. G Grosser and Dr. J. Geyer (University of Gießen, Germany) and characterized previously [27]. After receipt, the cell line was authenticated by stimulation of the OATP2B1 expression with tetracycline and quantifying the OATP2B $1 \mathrm{mRNA}$ expression by qRT-PCR. Cells were cultured under standard cell culture conditions with DMEM/Ham's F12 medium supplemented with $10 \%$ FCS, $4 \mathrm{mM}$ glutamine, $100 \mathrm{U} / \mathrm{ml}$ penicillin, and $100 \mu \mathrm{g} / \mathrm{ml}$ streptomycin sulfate. To generate OATP2B1 overexpression, cells were treated $72 \mathrm{~h}$ before the assay with $1 \mu \mathrm{g} / \mathrm{ml}$ tetracycline, and the overexpression of OATP2B1 compared to the non-tetracycline treated cells was confirmed in each assay by using the control inhibitor naringin.

\subsection{Cytotoxicity Assay}

Prior to the OATP inhibition assays, possible cytotoxic effects of the compounds investigated were assessed using the Cytotoxicity Detection Kit according to the manufacturer's instructions. This assay quantifies the activity of the lactate dehydrogenase released from the cytosol of damaged cells. None of the test compounds had $>30 \%$ cytotoxicity at the highest concentration used $(100 \mu \mathrm{M})$. Moreover, in the flow cytometry assays no shift of the cell populations in the forward/sideward scatter occurred with any of the compounds at any concentration, indicating the lack of any short-term cytotoxic effects possibly influencing the results.

\subsection{OATP1B1/1B3 Inhibition Assay (8-FcA Flow Cytometry Uptake Assay)}

Inhibition of OATP1B1 and OATP1B3 was analyzed by measuring the uptake of the fluorescent substrate 8 -FcA into HEK293 cells overexpressing the respective OATP as described previously [28]. Cells transfected with the empty control vector served as a control. In brief, cells were incubated with medium containing $2.5 \mu \mathrm{M} 8$-FcA with or without the compounds tested for $10 \mathrm{~min}$ at $37^{\circ} \mathrm{C}$. After washing, intracellular 8-FcA fluorescence was measured in a MACSQuant 10 Analyzer flow cytometer. In each sample 30,000 cells were counted. Cell debris was eliminated by gating the viable cells in the forward versus side scatter. For determination of the inhibitor effects, the ratio between the median fluorescence of intracellular 8-FcA with and without inhibitor was calculated and normalized to the control cell line. Each concentration $(0.1-100 \mu \mathrm{M})$ was tested eight times, and each experiment was performed 3-5 times. Concentration-response curves and $\mathrm{IC}_{50}$ values were calculated by GraphPad Prism version 8.3.1 (GraphPad Software Inc., La Jolla, CA, USA) using the four-parameter fit (sigmoidal dose-response curves with variable slope).

\subsection{OATP2B1 Inhibition Assay (DBF Flow Cytometry Uptake Assay)}

OATP2B1 inhibition was analyzed by measuring the uptake of its fluorescent substrate DBF [29] into HEK293 cells overexpressing OATP2B1. Data were normalized to the values obtained with cells not treated with tetracycline and thus without overexpression of OATP2B1. The assay was conducted as described for OATP1B1 and OATP1B3 inhibition using $1 \mu \mathrm{M}$ of DBF instead of 8-FcA. 
Fig. 2 Concentration-dependent effect of the polymethoxyflavones on the OATP1B1 (a) and OATP1B3 (b) activity. For determination of the inhibitor effects, the ratio between the median fluorescence of intracellular 8-FcA with and without inhibitor was calculated in OATP-overexpressing cells and normalized to the control cell line. Each curve depicts the results of 4-6 experiments, and data are expressed as mean $\pm \mathrm{SEM}$

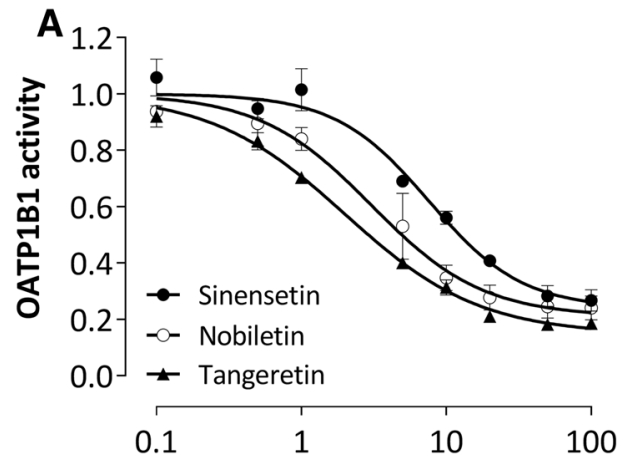

Concentration $[\mu \mathrm{M}]$

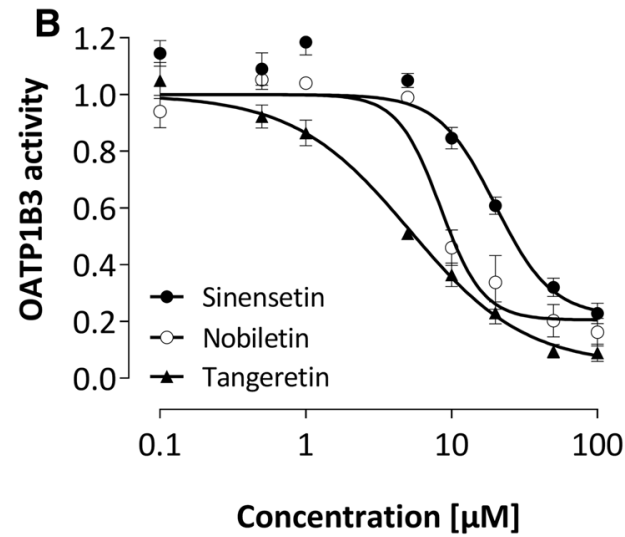

Table 1 Inhibition potency of the flavonoids and control inhibitors

\begin{tabular}{|c|c|c|c|}
\hline & $\begin{array}{l}\text { ОАТР1B1 } \\
\mathrm{IC}_{50}[\mu \mathrm{M}]\end{array}$ & $\begin{array}{l}\text { ОАТР1B3 } \\
\mathrm{IC}_{50}[\mu \mathrm{M}]\end{array}$ & $\begin{array}{l}\text { OATP2B1 } \\
\mathrm{IC}_{50}[\mu \mathrm{M}]\end{array}$ \\
\hline \multicolumn{4}{|c|}{ Polymethoxyflavones } \\
\hline Nobiletin & $2.1 \pm 0.7$ & $6.6 \pm 0.4$ & $1.6 \pm 0.4$ \\
\hline Sinensetin & $8.0 \pm 2.6$ & $21.1 \pm 3.4$ & $5.4 \pm 0.6$ \\
\hline Tangeretin & $4.8 \pm 1.7$ & $5.6 \pm 1.0$ & $1.6 \pm 0.8$ \\
\hline \multicolumn{4}{|c|}{ Flavonoid rutinosides } \\
\hline Didymin & nd & nd & $3.8 \pm 1.5$ \\
\hline Hesperidin & nd & nd & $8.3 \pm 1.2$ \\
\hline Narirutin & nd & nd & $14.2 \pm 3.5$ \\
\hline \multicolumn{4}{|c|}{ Control inhibitor } \\
\hline Rifampicin & $2.4 \pm 0.9[28]$ & $2.1 \pm 1.0[28]$ & \\
\hline Naringin & nd & nd & $6.9 \pm 1.4$ \\
\hline
\end{tabular}

$I C_{50}$ half maximal inhibitory concentration, OATP organic anion transporting polypeptide, $n d$ not determinable $(>100 \mu \mathrm{M})$. Data are presented as mean \pm SD for $n=3-4$ experiments. $\mathrm{IC}_{50}$ values were calculated by GraphPad Prism version 8.3.1 (GraphPad Software Inc., La Jolla, CA, USA) using the four-parameter fit (sigmoidal doseresponse curves with variable slope)

\section{Results}

The polymethoxyflavones nobiletin, sinensetin, and tangeretin all decreased 8-FcA fluorescence in OATP1B1- and OATP1B3-overexpressing cells concentration dependently but not in the control cell line, clearly indicating inhibition of these OATPs and excluding unspecific effects such as quenching (Fig. 2). The $\mathrm{IC}_{50}$ values for inhibition were in the lower micromolar range $(2-8 \mu \mathrm{M}$ for OATP1B1 and 6-21 $\mu \mathrm{M}$ for OATP1B3; Table 1) with nobiletin being the most potent inhibitor for OATP1B1 and tangeretin being the most potent inhibitor for OATP1B3. Comparison of the $\mathrm{IC}_{50}$ values of the polymethoxyflavones with the well-known strong OATP1B1/1B3 inhibitor rifampicin $\left(\mathrm{IC}_{50}\right.$ about $2 \mu \mathrm{M})$ revealed that these natural compounds are strong inhibitors with the exception of sinensetin whose potency for OATP1B3 was about ten times lower than that of rifampicin (Table 1). In contrast, the flavonoid rutinosides were not relevant inhibitors of these OATPs (Table 1).

All flavonoids investigated decreased DBF fluorescence in OATP2B1 overexpressing cells but not in the parental cell line demonstrating OATP2B1 inhibition with $\mathrm{IC}_{50}$ values in the lower micromolar range (2-14 $\mu$ M Fig. 3, Table 1). The
Fig. 3 Concentration-dependent effect of citrus flavonoids on OATP2B1 activity. For determination of the inhibitor effects, the ratio between the median fluorescence of intracellular 8-FcA with and without inhibitor was calculated in OATPoverexpressing cells and normalized to the control cell line. Each curve depicts the results of 3-4 experiments, and data are expressed as mean \pm SEM
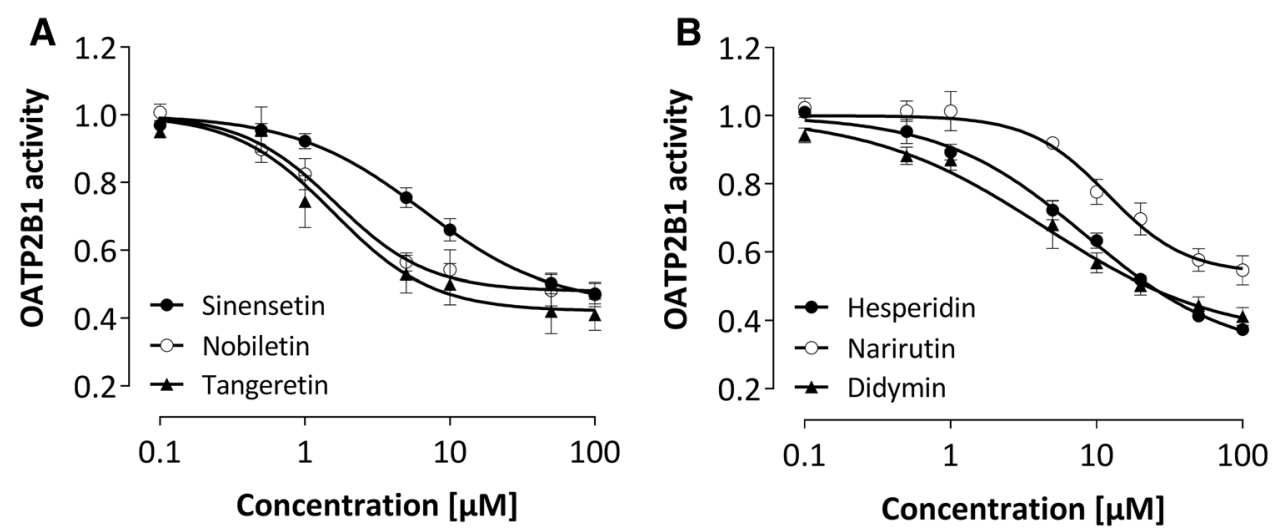
potency was similar or even greater compared to the known and potent OATP2B1-inhibitor naringin $(6.9 \mu \mathrm{M}$, Table 1$)$.

\section{Discussion}

Flavonoids belong to daily nutritional components, and citrus flavonoids are used as traditional medicines and promoted as dietary supplements [1, 8, 9]. Interactions of several fruit juices, especially grapefruit juice, with clinically used drugs are well known and can be partially attributed to inhibition of OATPs [17, 19, 23, 30].

The drug uptake transporters OATP1B1 and OATP1B3 are key players in the hepatic uptake of numerous drugs in humans and influence the pharmacokinetics of these drugs, such as statins, telmisartan, irbesartan, and bosentan [17, 18, 21]. Inhibition of these OATPs can lead to increased plasma concentrations and decreased elimination of drugs that are substrates [17, 21]. This might provoke increased toxicity but also diminished clinical efficacy for drugs such as statins that exert their wanted effects in the liver [31]. So far, there are only sparse in vitro data for the OATP1B1/1B3-inhibiting properties of citrus fruits/juices or citrus flavonoids. To the best of our knowledge, this is the first report of the polymethoxyflavones nobiletin, sinensetin, and tangeretin being inhibitors of OATP1B1 and OATP1B3. These results reveal that polymethoxyflavones are the perpetrators of the OATP1B1 and OATP1B3 inhibition of clementine and mandarin juice we observed earlier [5]. The inhibition potency is high and for OATP1B1 in the same range as for the wellknown and potent inhibitor rifampicin (Table 1). However, to be clinically relevant, OATP1B1/1B3 inhibitors need to reach sufficient systemic concentrations. For the three polymethoxyflavones tested in this study, there are no data on pharmacokinetics in humans at all, making a prediction of the clinical relevance impossible. In rats, the bioavailability of nobiletin and tangeretin is predicted not to be very high (36\% and $27 \%$, respectively) $[32,33]$. Therefore, one might speculate that the systemic concentrations after consumption of citrus fruits/juices might not be high enough for inhibition of OATP1B1/1B3. However, pure nobiletin, sinensetin, and tangeretin or medicines made of polymethoxyflavone-rich pericarp are promoted for their manifold health-promoting effects [9], Ingestion of these high amounts of polymethoxyflavones probably leads to much higher systemic concentrations, likely carrying the risk of interactions with concomitantly used drugs being OATP1B1/1B3 substrates.

Only recently has OATP2B1 been recognized as the primary intestinal isoform that can mediate intestinal absorption of drugs and drug-drug and food-drug interactions [19, 20, $22,34]$. Moreover, it seems to be the main OATP isoform mediating interactions between citrus juices and drugs, which were originally attributed to OATP1A2 [19, 22, 23, 34-36].
We confirmed OATP2B1 inhibition by nobiletin, tangeretin, and hesperidin $[24,37,38]$. The $\mathrm{IC}_{50}$ values did not coincide in any case with previously published values, but it is common experience that absolute values cannot be compared between different assay systems with different expression levels and different substrates. Moreover, our data demonstrate for the first time that sinensetin, didymin, and narirutin also inhibit OATP2B1 with narirutin being the inhibitor with the lowest potency (Table 1). The potency was similar or even exceeded that of the well-known OATP2B1 inhibitor naringin (Table 1).

Whereas inhibition of hepatic OATPs provokes increased plasma concentrations of the respective substrates, inhibition of intestinal OATP2B1 leads to decreased bioavailability $[17,18]$. Although OATP2B1 is expressed in the intestine and in the liver, the concentrations of orally administered drugs or food components are normally much higher in the intestine compared to the portal blood, which might be the reason why OATP2B1 inhibitors decrease the plasma concentration of OATP2B1 substrates as postulated, e.g., for the decrease of the area under the curve (AUC) of aliskiren by grapefruit and orange juice [39, 40], the reduced bioavailability of celiprolol by orange juice [41], and for the decrease in exposure of rosuvastatin by ronacaleret [42]. Our data demonstrate that all flavonoids tested are inhibitors of OATP2B1 and might thus contribute to the effects of citrus juices observed in humans. The concentrations of the flavonoids in juices and thus in the intestine vary between citrus species and between different lots. Thus, the interaction potential depends not only on the amount of juice or fruit ingested, but also on the citrus species and the batch. Flavonoid concentrations $>100 \mu \mathrm{M}$ (up to $20 \mathrm{mM}$ ) in fruit or juice have been reported [3, 5, 43, 44], often profoundly exceeding effective concentrations for OATP2B1 inhibition $\left(\mathrm{IC}_{50}=8.3 \mu \mathrm{M}\right)$. When consumed as nutritional supplements or medicines, intestinal concentrations of these flavonoids might even be higher and thus the risk of interactions with drugs that are OATP2B1 substrates is doubtlessly even higher.

Limitations: (1) Our study neither investigated whether the inhibition of OATP activity by the flavonoids is competitive or non-competitive nor studied possible structure-activity relationships. Thus, the underlying mechanism of inhibition remains unclear. (2) We did not test the metabolites of the flavonoids generated in vivo, which might also contribute to their drug-drug interaction potential. (3) We only tested the interaction of the flavonoids with probe drugs.

\section{Conclusions}

In conclusion, we have verified that hesperidin, nobiletin, and tangeretin are OATP2B1 inhibitors and also proved sinensetin, didymin, and narirutin to potently inhibit this 
uptake transporter. Considering the high concentrations sometimes reached in the intestine after ingestion of citrus juices or fruits, interaction with OATP2B1 substrate drugs is very likely. In addition, we have demonstrated for the first time strong to moderate OATP1B1 and OATP1B3 inhibiting properties of the polymethoxyflavones nobiletin, sinensetin, and tangeretin, which might be a risk when consumed as medicine or as dietary supplements.

Acknowledgements Open Access funding provided by Projekt DEAL. The authors thank Corina Mueller and Stephanie Rosenzweig for excellent technical assistance, Dietrich Keppler for providing the HEKOATP1B1/1B3 cell lines and Gary Grosser and Joachim Geyer for providing the HEK-OATP2B1 cell line.

Data Availability All raw data generated during this study will be made available on request.

\section{Compliance with Ethical Standards}

Funding This work did not receive any special funding

Conflict of interest The authors have declared that no conflicts of interest exist.

Open Access This article is licensed under a Creative Commons Attribution-NonCommercial 4.0 International License, which permits any non-commercial use, sharing, adaptation, distribution and reproduction in any medium or format, as long as you give appropriate credit to the original author(s) and the source, provide a link to the Creative Commons licence, and indicate if changes were made. The images or other third party material in this article are included in the article's Creative Commons licence, unless indicated otherwise in a credit line to the material. If material is not included in the article's Creative Commons licence and your intended use is not permitted by statutory regulation or exceeds the permitted use, you will need to obtain permission directly from the copyright holder. To view a copy of this licence, visit http://creativecommons.org/licenses/by-nc/4.0/.

\section{References}

1. Vogiatzoglou A, Mulligan AA, Lentjes MAH, Luben RN, Spencer JPE, Schroeter H, Khaw K-T, Kuhnle GGC. Flavonoid intake in European adults (18 to 64 years). PLoS ONE. 2015;10:e0128132.

2. Barreca D, Gattuso G, Bellocco E, Calderaro A, Trombetta D, Smeriglio A, Laganà G, Daglia M, Meneghini S, Nabavi SM. Flavanones: citrus phytochemical with health-promoting properties. BioFactors. 2017;43:495-506.

3. Gattuso G, Barreca D, Gargiulli C, Leuzzi U, Caristi C. Flavonoid composition of citrus juices. Molecules. 2007;12:1641-73.

4. Khan MK, Huma ZW, Dangles O. A comprehensive review on flavanones, the major citrus polyphenoles. J Food Comp Anal. 2014;33:85-104

5. Theile D, Hohmann N, Kiemel D, Gattuso G, Barreca D, Mikus G, Haefeli WE, Schwenger V, Weiss J. Clementine juice has the potential for drug interactions - in vitro comparison with grapefruit and mandarin juice. Eur J Pharm Sci. 2017;97:247-56.
6. Lai C-S, Wu J-C, Ho C-T, Pan M-H. Disease chemopreventive effects and molecular mechanisms of hydroxylated polymethoxyflavones. BioFactors. 2015;41:301-13.

7. Li S, Pan M-H, Lo C-Y, Tan D, Wang Y, Shahidi D, Ho C-T. Chemistry and health effects of polymethoxyflavones and hydroxylated polymethoxyflavone. J Funct Foods. 2009;1:2-12.

8. Lv X, Zhao S, Ning Z, Zeng H, Shu Y, Tao O, Xiao C, Lu C, Liu $\mathrm{Y}$. Citrus fruits as a treasure trove of active natural metabolites that potentially provide benefits for human health. Chem Cent J. 2015;9:68

9. Yu X, Sun S, Guo Y, Liu Y, Yang D, Li G, Lü S. Citri Reticulatae Pericarpium (Chenpi): Botany, ethnopharmacology, phytochemistry, and pharmacology of a frequently used traditional. Chin Med J Ethnopharmacol. 2018;220:265-82.

10. Yao Q, Lin M-T, Zhu Y-D, Xu H-L, Zhao Y-Z. Recent trends in potential therapeutic applications of the dietary flavonoid didymin. Molecules. 2018;23:E2547.

11. Benavente-García O, Castillo J. Update on uses and properties of citrus flavonoids: new findings in anticancer, cardiovascular, and anti-Inflammatory activity. J Agric Food Chem. 2008;56:6185-205.

12. Xu J-J, Wu X, Li M-M, Li G-Q, Yang Y-T, Luo H-J, Huang W-H, Chung HY, Ye W-C, Wang G-C, Li Y-L. Antiviral activity of polymethoxylated flavones from "Guangchenpi", the edible and medicinal pericarps of citrus reticulata 'Chachi'. J Agric Food Chem. 2014;62:2182-9.

13. Walle T. Methylation of dietary flavones greatly improves their hepatic metabolic stability and intestinal absorption. Mol Pharm. 2007;4:826-32.

14. Manach C, Morand C, Gil-Izquierdo A, Bouteloup-Demange C, Rémésy C. Bioavailability in humans of the flavanones hesperidin and narirutin after the ingestion of two doses of orange juice. Eur J Clin Nutr. 2003;57:235-42.

15. Cermak R, Wolffram $\mathrm{S}$. The potential of flavonoids to influence drug metabolism and pharmacokinetics by local gastrointestinal mechanisms. Curr Drug Metab. 2006;7:729-44.

16. Boonpawa R, Spenkelink A, Punt A, Rietjens IMCM. Physiologically based kinetic modeling of hesperidin metabolism and its use to predict in vivo effective doses in humans. Mol Nutr Food Res. 2017;61:1-14.

17. Shitara Y, Maeda K, Ikejiri K, Yoshida K, Horie TY. Clinical significance of organic anion transporting polypeptides (OATPs) in drug disposition: their roles in hepatic clearance and intestinal absorption. Biopharm Drug Dispos. 2013;34:45-78.

18. Hagenbuch B, Meier PJ. Organic anion transporting polypeptides of the OATP/SLC21 family: phylogenetic classification as OATP/ SLCO superfamily, new nomenclature and molecular/functional properties. Pflügers Arch Eur J Physiol. 2004;447:653-65.

19. McFeely SJ, Wu L, Ritchie TK, Unadkat J. Organic anion transporting polypeptide $2 \mathrm{~B} 1$-more than a glass-full of drug interactions. Pharmacol Ther. 2019;196:204-15.

20. Tamai I, Nakanishi T. OATP transporter-mediated drug absorption and interaction. Curr Opin Pharmacol. 2013;13:859-63.

21. Shitara Y. Clinical importance of OATP1B1 and OATP1B3 in drug-drug interactions. Drug Metab Pharmacokinet. 2011;26:220-7.

22. Drozdzik M, Busch D, Lapczuk J, Müller J, Ostrowski M, Kurzawski M, Oswald S. Protein abundance of clinically relevant drug transporters in the human liver and intestine: a comparative analysis in paired tissue specimens. Clin Pharmacol Ther. 2019;105:1204-12.

23. Dolton MJ, Roufogalis BD, McLachlan AJ. Fruit juices as perpetrators of drug interactions: the role of organic anion-transporting polypeptides. Clin Pharmacol Ther. 2012;92:622-30.

24. Johnson E, Won CS, Köck K, Paine MF. Prioritizing pharmacokinetic drug interaction precipitants in natural products: application 
to OATP inhibitors in grapefruit juice. Biopharm Drug Dispos. 2017;38:251-9.

25. König J, Cui Y, Nies AT, Keppler D. Localization and genomic organization of a new hepatocellular organic anion transporting polypeptide. J BiolChem. 2000;275:23161-8.

26. König J, Cui Y, Nies AT, Keppler D. A novel human organic anion transporting polypeptide localized to the basolateral hepatocyte membrane. Am J Physiol Gastroint Liver Physiol. 2000;278:G156-G164164.

27. Grosser G, Döring B, Uegele B, Geyer J, Kulling SE, Soukup ST. Transport of the soy isoflavone diadzein and its conjugative metabolites by the carriers SOAT, NTCP, OAT4, and OATP2B1. Arch Toxicol. 2015;89:2253-63.

28. Weiss J, Theile D, Spalwisz A, Burhenne J, Riedel K-D, Haefeli WE. Influence of sildenafil and tadalafil on the enzyme- and transporter-inducing effects of bosentan and ambrisentan in LS180 cells. Biochem Pharmacol. 2013;85:265-73.

29. Izumi S, Nozaki Y, Komori KMT, Takenaka O, Kusuhara H, Sugiyama Y. Investigation of the impact of substrate selection on in vitro organic anion transporting polypeptide 1B1 inhibition profiles for the prediction of drug-drug interactions. Drug Metab Dispos. 2015;43:235-47.

30. Seden K, Dickinson L, Khoo S, Back D. Grapefruit-drug Interactions. Drugs. 2010;70:2373-407.

31. Gessner A, König J, Fromm MF. Clinical aspects of transporter-mediated drug-drug interactions. Clin Pharmacol Ther. 2019; 105:1386-94.

32. Hung W-L, Chang W-S, Lu W-C, Wie G-J, Wang Y, Ho C-T, Hwang LS. Pharmacokinetics, bioavailability, tissue distribution and excretion of tangeretin in rat. J Food Drug Anal. 2018;26:849-57.

33. Kumar A, Devaraj VC, Giri KC, Giri S, Rajagopal S, Mullangi R. Development and validation of a highly sensitive LC-MS/ MS-ESI method for the determination of nobiletin in rat plasma: application to a pharmacokinetic study. Biomed Chromatogr. 2012;26:1464-71.

34. Unger MS, Mudunuru J, Schwab M, Hopf C, Drewes G, Nies AT, Zamek-Gliszczynski MJ, Reinhard FBM. Clinically relevant OATP2B1 inhibitors in marketed drug space. Mol Pharm. 2020;17:488-98.

35. Bailey DG. Fruit juice inhibition of uptake transport: a new type of food-drug interaction. Br J Clin Pharmacol. 2010;70:645-55.

36. Chen M, Hu S, Li Y, Gibson AA, Fu Q, Baker SD, Sparreboom A. Role of Oatp2b1 in drug absorption and drug-drug interactions. Drug Metab Dispos. 2020;48:419-25.

37. Shirasaka Y, Shichiri M, Mori T, Nakanishi T, Tamai I. Major active components in grapefruit, orange, and apple juices responsible for OATP2B1-mediated drug interactions. J Pharm Sci. 2013;102:3418-26.

38. Satoh H, Yamashita F, Tsujimoto M, Murakami H, Koyabu N, Ohtani H, Sawada Y. Citrus juices inhibit the function of human organic anion-transporting polypeptide OATP-B. Drug Metab Dispos. 2005;33:518-23.

39. Tapaninen T, Neuvonen PJ, Niemi M. Grapefruit juice greatly reduces the plasma concentrations of the OATP2B1 and CYP3A4 substrate aliskiren. Clin Pharmacol Ther. 2010;88:339-42.

40. Tapaninen T, Neuvonen PJ, Niemi M. Orange and apple juice greatly reduce the plasma concentrations of the OATP2B1 substrate aliskiren. Br J Clin Pharmacol. 2011;71:718-26.

41. Lilja JJ, Juntti-Patinen L, Neuvonen PJ. Orange juice substantially reduces the bioavailability of the beta-adrenergic-blocking agent celiprolol. Clin Pharmacol Ther. 2004;75:184-90.

42. Johnson M, Patel D, Matheny C, Ho M, Chen L, Ellens H. Inhibition of intestinal OATP2B1 by the calcium receptor antagonist ronacaleret results in a significant drug-drug interaction by causing a 2-fold decrease in exposure of rosuvastatin. Drug Metab Dispos. 2017;45:27-34.

43. Nogata Y, Sakamoto K, Shiratsuchi H, Ishii T, Yano M, Ohta H. Flavonoid composition of fruit tissues of citrus species. Biosci Biotechnol Biochem. 2006;70:178-92.

44. Dhuique-Mayer C, Caris-Veyrat C, Ollitrault P, Curk F, Amiot $\mathrm{M}-\mathrm{J}$. Varietal and interspecific influence on micronutrient contents in citrus from the Mediterranean area. J Agric Food Chem. 2005;53:2140-5. 